\title{
NOÇÕES BÁSICAS ACERCA DAS RESTRIÇÕES VERTICAIS NO DIREITO CONCORRENCIAL BRASILEIRO: DA LICITUDE À ILICITUDE “PER SE" À LUZ DA RESOLUÇÃO N 20 DO CADE
}

\author{
A BRIEF REVIEW OF THE VERTICAL RESTRAINTS IN BRAZILIAN \\ COMPETTION LAW: THE LEGALITY OR ILLEGATY "PER SE" IN CADE \\ RESOLUTION Nr. 20.
}

\author{
DANILO BRUM DE MAGALHÃES JÚNIOR \\ Acadêmico de Direito na Universidade do Vale do Rio dos Sinos. Bolsista de Iniciação Científica. \\ danilo_junior@live.com
}

\section{RESUMO}

O presente trabalho tem por objetivo apresentar noções básicas acerca das restrições verticais no direito concorrencial, investigando a abordagem dada pela legislação brasileira, pelos juristas e pelos economistas ao assunto. Para tanto, entendeu-se necessário trazer ao conhecimento do leitor o avanço da legislação antitruste no Brasil, com enfoque na Constituição Federal e na lei 12.529/11, para, então, apresentar o conceito de restrição vertical. Após, é feita uma análise de como se da a ilicitude destas práticas perante o direito brasileiro.Como conclusão, defende-se que o tema das restrições verticais no direito concorrencial pátrio ainda é muito polêmico e que o guia brasileiro de análise das restrições verticais, apesar de ser um avanço à sua época, atualmente precisa de modernizações para conseguir enfrentar esta problemática da sociedade contemporânea.

]

Palavras-chave: Restrições Verticais; Política de Defesa da Concorrência; Condutas Anticompetitivas.

\begin{abstract}
This study aims to intoduce a brief review of the vertical restraints in brazilian competition law, investigating the approach of the Brazilian legislation, the jurists and the economists. For both, it seems necessary to introduce the progress of the antitrust law in Brazil, particularly the brazilian Constitution and the new antitrust law, for then introduce the concept of vertical restraints. Then, an analysis is made for to understand how these practices become illicit opposite the brazilian law. As a conclusion, it is advocated that the vertical restraints are polemic topic in the antitrust law and the brazilian Vertical restraints guidelines, although modern in the 90's years, today needs innovations for to oppose the problems of contemporary society.
\end{abstract}

Keywords: Vertical Restraints; Antitrust Policy; anticompetitive conducts.

\section{SUMÁRIO}

INTRODUÇAO; 1 A LEI 12.29/11 E A REPRESSÃO ÀS CONDUTAS ANTICOMPETITIVAS; 2 O QUE SÃO RESTRIÇÕES VERTICAIS? 3.1 Conceito de Restrição Vertical; 3 DA (I)LICITUDE DAS RESTRIÇÕES VERTICAIS; 3.1 Caracterização da Conduta; 3.2 Análise das condições estruturais e/ou institucionais; 3.2.1 Mercado Relevante; 3.2.2 Posição Dominante; 3.3 Análise da Conduta específica; 3.3.1 Identificação das Eficiências Econômicas; 3.3.2 Identificação das Eficiências Econômicas; 3.3.2 Identificação dos Efeitos Anticoncorrenciais; 3.3.3 Ponderação dos Efeitos Anticompetitivos e das Eficiências Econômicas - A regra da razão; CONCLUSÃO; REFERÊNCIAS. 


\section{INTRODUÇÃO}

Para desenvolver suas atividades, as empresas precisam obter insumos, tais como matérias-primas, e escoar a sua produção. Dependendo do contexto econômico e da estratégia de mercado, é possível que a empresa decida adquirir matéria-prima de terceiros e/ou realizar venda por meio de outros agentes. Nessa hipótese, as empresas utilizarão dos chamados acordos verticais .

Os acordos verticais são, então, aqueles celebrados entre agentes econômicos de mercados relevantes diferentes, mas concatenados no processo produtivo ou de distribuição, isto é, atuam em diferentes níveis da cadeia produtiva. No entanto, para fazer melhor uso dos acordos verticais e adaptar suas necessidades às relações contratuais, os agentes econômicos utilizam certas cláusulas, que no direito concorrencial são conhecidas como restrições verticais, que, por sua vez, são objetos do presente estudo.

Historicamente, tais cláusulas de restrições verticais possuem tratamentos diferenciados, passando da licitude à ilicitude per se . Mas hoje, considerando o contexto do direito concorrencial brasileiro, pode-se dizer que tanto a resolução $n^{\circ}$ 20/1999 do Conselho Administrativo de Defesa Econômica (CADE) quanto a lei antitruste brasileira (Lei 12.529 de 2011), indicam claramente a utilização da chamada regra da razão, que, como veremos, utiliza o balanceamento das eficiências econômicas e dos efeitos anticompetitivos gerados pelas restrições verticais, ou seja, para definir a fronteira entre o lícito e o ilícito no direito antitruste brasileiro, deve-se ter presente o impacto, ou efeitos, das diversas condutas sobre o mercado

0 problema é que quando fala-se em eficiências econômicas das restrições verticais estamos entrando em um dos assuntos mais polêmicos do direito antitruste. Isto porque, não há um consenso da doutrina e da jurisprudência sobre em que medida as eficiências econômicas geradas pelas restrições verticais são capazes de suplantar o dano à concorrência a que dão origem .

O objetivo do presente trabalho, portanto, é fazer uma breve revisão da literatura antitruste, bem como de determinados aspectos operacionais e legais no âmbito da legislação brasileira de defesa da concorrência, sobre práticas restritivas verticais. 
NOÇÕES BÁSICAS ACERCA DAS RESTRIÇÕES VERTICAIS NO DIREITO CONCORRENCIAL BRASILEIRO: DA LICITUDE À ILICITUDE “PER SE" À LUZ DA RESOLUÇÃO N 20 DO CADE

DANILO BRUM DE MAGALHÃES JÚNIOR

Este é um momento muito importante para discutirmos tais práticas no direito concorrencial, uma vez que o atual presidente do CADE, Dr. Vinícius Marques de Carvalho, já manifestou sua expectativa de, em breve, lançar o novo guia de análise das restrições verticais .

\section{A LEI 12.529/11 E A REPRESSÃO ÀS CONDUTAS ANTICOMPETITIVAS}

O direito da concorrência no Brasil encontra-se positivado por meio da Lei $n^{\circ}$ 12.529/11, que introduziu no ordenamento jurídico brasileiro um microssistema , cujo objeto é a tutela da concorrência em nosso país, regulamentando o artigo 173, §4 da Constituição Federal.

A Lei 12.529/11 organiza o Sistema Brasileiro de Defesa da Concorrência (SBDC), que é composto por dois órgãos: (i) Conselho Administrativo de Defesa Econômica (CADE), autarquia especial, ligada ao Ministério da Justiça e (ii) Secretaria de Acompanhamento Econômico (SEAE), do Ministério da Fazenda.

O SBDC possui três modos de atuação : (i) preventiva; (ii) repressiva; e (iii) educativa. A primeira vertente se pauta na estrutura de mercado para aprovar atos de concentração (fusões, aquisições e incorporações de empresas) e o terceiro foco que corresponde ao papel de difusão da cultura da concorrência, via parceria com instituições para a realização de seminários, palestras, cursos e publicações de relatórios e matérias em revistas especializadas, visando um maior interesse acadêmico pela área, o incremento da qualidade técnica e da credibilidade das decisões emitidas e a consolidação das regras antitruste junto à sociedade.

Mas é o caráter repressivo que atrai a maior atenção não só deste trabalho, mas como dos agentes envolvidos com o direito antitruste, pois indica uma postura combativa por parte da autoridade competente para assegurar o mandamento legal e tutelar pela concorrência frente a uma conduta ilícita de determinado agente econômico. Para configurar um ilícito antitruste, é preciso enquadrar a conduta na definição do artigo 36 da lei 12.529/11.

Ocorre, no entanto, que o texto do caput do art. 36 de nossa lei antitruste, é bastante amplo, abrangendo infinitos atos ou contratos que podem ser praticados ou celebrados em restrição à concorrência e práticas abusivas. Por esta razão, o mesmo art. 36, em seu § 3o, menciona série de condutas que, caso impliquem a concomitante incidência do caput e seus incisos, consubstanciarão infrações à ordem econômica. Entretanto, tendo em vista que no Brasil não há “infração per se”, deve-se ter em mente que o elenco do § 3o, é meramente exemplificativo, devendo estas condutas, para serem declaradas ilícitas, terem seus efeitos abusivos ou anticompetitivos comprovados, conforme o caput do art. 36. 
NOÇÕES BÁSICAS ACERCA DAS RESTRIÇÕES VERTICAIS NO DIREITO CONCORRENCIAL BRASILEIRO: DA LICITUDE À ILICITUDE “PER SE" À LUZ DA RESOLUÇÃO N 20 DO CADE

DANILO BRUM DE MAGALHÃES JÚNIOR

Por lógica, percebe-se que a redação do caput do artigo 36 levaria a condenação todos os atos entre agentes econômicos que infrinjam a concorrência. Entretanto, isso poderia não ser benéfico para a economia, pois, ao fim e ao cabo, alguns atos, mesmo anticoncorrenciais, podem trazer fatores de desenvolvimento, incluindo benefícios para os consumidores. Por conta disto, passaremos agora a estudar as práticas restritivas verticais, com a finalidade de discutirmos se há ou não possibilidade de benefícios em práticas anticompetitivas.

\section{O QUE SÃO RESTRIÇÕES VERTICAIS?}

As infrações à ordem econômica podem ser exercidas mediante uma série de condutas, dentre as quais se situam os acordos firmados entre os agentes econômicos. Pelo fato de permitir o abuso do poder econômico, viabilizando a reprodução de condições monopolísticas, os acordos entre agentes econômicos são tradicionalmente regulamentados pelas legislações antitruste de todo o mundo. Não divergindo, os legisladores brasileiros determinaram expressamente em nossa lei antitruste que são considerados ilícitos os acordos entre agentes econômicos que tenham por objeto, ou possam produzir os seguintes efeitos: (i)limitar, falsear ou de qualquer forma prejudicar a livre concorrência ou a livre iniciativa; (ii) dominar mercado relevante de bens ou serviços; (iii) aumentar arbitrariamente os lucros; e (iv)exercer de forma abusiva posição dominante .

Ocorre que, em um mercado concorrencial, os diversos sujeitos que se dedicam à atividade econômica, em especial as empresas pelo destaque que essa forma de organização tem no período atual do capitalismo, podem competir em dois planos: um primeiro, relativo a uma concorrência entre marcas (interbrand competition) ou horizontal, que é aquele em que observamos a concorrência (efetiva ou potencial) de sujeitos que atuam num mesmo mercado na oferta ou na procura de produtos ou serviços; do outro lado, podemos olhar para a concorrência sob um prisma vertical, ou intramarcas (intrabrand competition), que é aquela decorrente do relacionamento de duas ou mais empresas interligadas a partir de alguma relação vertical, isto é, quando uma empresa atua no mercado de insumos ou matérias-primas de outra, dentro de uma cadeia produtiva, ou quando uma empresa dedica-se à distribuição dos produtos ou serviços de outra. Nesse caso, a concorrência vertical se dá, por exemplo, pela disputa entre os diversos revendedores do produto de uma determinada marca .

Tendo em vista o mercado em que atuam os agentes econômicos celebrantes e os efeitos provocados pelos acordos, a doutrina os classifica em duas espécies, quais sejam os 
NOÇõES BÁSICAS ACERCA DAS RESTRIÇÕES VERTICAIS NO DIREITO CONCORRENCIAL BRASILEIRO: DA LICITUDE À ILICITUDE “PER SE" À LUZ DA RESOLUÇÃO N 20 DO CADE

DANILO BRUM DE MAGALHÃES JÚNIOR

acordos horizontais e os acordos verticais. Os primeiros caracterizam-se pelo fato de envolver agentes econômicos que atuam em um mesmo mercado relevante, encontrando-se em direta relação de concorrência. Já os acordos verticais, disciplinam relações entre agentes econômicos que atuam em mercados relevantes diferentes, por diversas vezes complementares, como um acordo firmado entre produtor e distribuidor .

Os chamados acordos verticais, portanto, envolvem agentes econômicos que atuam em etapas diversas de uma mesma cadeia de comercialização/produção, constituindo uma alternativa ao processo de concentração de empresas, uma vez que cada um dos agentes mantém isolado seu centro de poder, ao contrário do que ocorre na concentração, em que há uma perda de autonomia. Na visão de Paula Forgioni , no entanto, a atuação conjunta das empresas causará nos mercados envolvidos praticamente os mesmos efeitos que decorreriam de uma prática concentracionista.

Deve-se ter em mente que os efeitos sentidos no mercado podem ser considerados prejudiciais ou benéficos, a depender do mercado sob análise. Isto porque, esse tipo de acordo pode restringir a concorrência entre os agentes econômicos distribuidores de um mesmo bem ou serviço (intraband competititon) e, ao mesmo tempo, estimular a concorrência no mercado relevante em que atua o produtor (interbrand competititon). Por este caráter duvidoso, o estudo das restrições verticais pode ser considerado um dos assuntos mais polêmico no direito concorrencial .Isto faz que necessitemos conhecer mais o universo dessas relações para compreendermos seus limites traçados pelo princípio da liberdade de concorrência.

\subsection{Conceito de Restrição Vertical}

Conceitos de "restrições verticais" podem ser encontradas em vários manuais de economia e em documentos legais. Por exemplo, conforme o já revogado Vertical Restraints Guidelines norte-americano :

Vertical restraints are arrangements between firms operating at different levels of the manufacturing or distribution chain (for example, between a manufacturer and a wholesaler or a wholesaler and a retailer) that restrict the conditions under which firms may purchase, sell or resell".

A comunidade europeia, com o objetivo de ajudar as empresas a avaliar, caso a caso, a compatibilidade dos acordos com as regras de concorrência, formulou um comunicado 
NOÇÕES BÁSICAS ACERCA DAS RESTRIÇÕES VERTICAIS NO DIREITO CONCORRENCIAL BRASILEIRO: DA LICITUDE À ILICITUDE “PER SE" À LUZ DA RESOLUÇÃO N 20 DO CADE

DANILO BRUM DE MAGALHÃES JÚNIOR

fornecendo um quadro analítico sobre as restrições verticais. No referido texto, a comunidade europeia conceituo restrições verticais como :

acordos ou práticas concertadas em que participam duas ou mais empresas, cada uma delas operando, para efeitos do acordo, a um nível diferente da produção ou da cadeia de distribuição, e que digam respeito aos termos em que as partes podem adquirir, vender ou revender certos bens ou serviços. Os acordos ou práticas concertadas dizem respeito aos termos em que as partes podem adquirir, vender ou revender certos bens e serviços. As presentes orientações expõem os princípios de apreciação dos acordos verticais a fim de verificar se não afectam a concorrência entre Estados-Membros.

Para a doutrina jurídico-econômica, restrições verticais são estipulações contratuais, ou condições impostas por um dos participantes ao longo da cadeia vertical sobre outro participante, que restringem a liberdade de atuação do distribuidor ou do fornecedor. Desta forma, entende-se que tal conduta trata-se de um mecanismo para promover a coordenação vertical e a realização de ganhos que não poderiam ser obtidos se as decisões fossem preservadas autonomamente para cada parte de uma transação .

No âmbito legislativo, a resolução $\mathrm{n}^{\circ} 20$ do Conselho Administrativo de Defesa Econômica (CADE), por meio do anexo I, letra $B$, conceitua restrição vertical da seguinte maneira:

As práticas restritivas verticais são restrições impostas por produtores/ofertantes de bens ou serviços em determinado mercado ("de origem") sobre mercados relacionados verticalmente - a "montante" ou a "jusante" - ao longo da cadeia produtiva (mercado "alvo").

Poderíamos, então, utilizando os conceitos legislativos e doutrinários acima, conceituar restrições verticais como: estipulações contratuais, geralmente inseridas por produtores/ofertantes de bens ou serviços em determinado mercado sobre mercados relacionados verticalmente ao longo da cadeia produtiva, que restringem a liberdade de atuação de uma das partes.

Dos conceitos apresentados, conclui-se parcialmente que as restrições verticais ocorrem, não entre agentes que em um cenário econômico normal se veriam em posição de concorrência natural, ao contrário, verifica-se que estes atos são praticados ao longo de uma cadeia produtiva por agentes que, presumivelmente operariam sob um regime de cooperação para maximizar os resultados de sua atividade. Ademais, há práticas restritivas que se desenvolvem tanto do produtor para o consumidor, passando pela estrutura de distribuição e 
NOÇÕES BÁSICAS ACERCA DAS RESTRIÇÕES VERTICAIS NO DIREITO CONCORRENCIAL BRASILEIRO: DA LICITUDE À ILICITUDE “PER SE" À LUZ DA RESOLUÇÃO Nº 20 DO CADE

DANILO BRUM DE MAGALHÃES JÚNIOR

pelo ponto de venda final, bem como práticas que se desenrolam no sentido contrário, ou seja, impostas pelos distribuidores aos produtores.

\section{DA (I)LICITUDE DAS RESTRIÇÕES VERTICAIS}

Nos Estados Unidos da América, as restrições verticais foram por muitos anos consideradas ilegais per se pelos Tribunais. Entretanto, perto do fim do século XX, com a crescente importância da Escola de Chicago, as restrições verticais passaram a ser vistas como arranjos prima facie eficientes e, portanto, benéficos aos consumidores .

No entanto, em 2007, após a Suprema Corte ter julgado o caso Leegin, alterando um precedente de noventa e seis anos ao determinar que acordos de Resale Price Management (RPM), de acordo com o qual uma empresa determina o preço de revenda do bem, não são ilegais per se, devendo ser submetidos à regra da razão .

Na União Européia, chegou-se também a mesma solução, em 20 de abril de 2010, com a edição do Regulamento n. ${ }^{\circ} 330 / 2010$, que lista condições necessárias para tornar lícitas as restrições verticais.

No contexto brasileiro, para considerarmos infrações à ordem econômica, as restrições verticais devem implicar a incidência, como já vimos, de qualquer dos incisos do artigo 36 da Lei Antitruste, ainda que de forma potencial.

Essa afirmação, apesar de ser simples a uma primeira vista, é aquela que encontra a maior dificuldade de explicação no direito antitruste, isto porque, diferente das outras áreas do direito positivo, onde há um leque de soluções à disposição do intérprete mais contido, o direito antitruste tem a flexibilidade como uma de suas características intrínsecas, iluminada por espectros bem mais amplos de interpretação.

Para Ticiana Nogueira da Cruz Lima , o SBDC deixa as decisões inteiramente a cargo do CADE, uma vez que a lei, não determina hipóteses que devam ser consideradas ilícitas. Segundo a autora, o sistema aceita mais de uma decisão possível na análise de atos prejudiciais à concorrência, a depender do caso concreto.

Ou seja, no direito antitruste brasileiro, se faz necessário analisar o impacto das diversas condutas sobre a dinâmica do mercado para a caracterização do lícito ou ilícito, isto porque há uma convicção, por parte da comunidade da defesa da concorrência, que se expressa na doutrina e na jurisprudência, de que o artigo 36, caput, da lei antitruste (Lei 12.529/11), não 
NOÇÕES BÁSICAS ACERCA DAS RESTRIÇÕES VERTICAIS NO DIREITO CONCORRENCIAL BRASILEIRO: DA LICITUDE À ILICITUDE “PER SE” À LUZ DA RESOLUÇÃO N² 20 DO CADE

DANILO BRUM DE MAGALHÃES JÚNIOR

contempla a possibilidade de ilegalidade per se na avalição de condutas anticompetitivas, e por isso, faz-se necessário a análise dos efeitos líquidos pela regra da razão.

Sobre o tema, Fábio Ulhoa Coelho destaca que "O CADE poderá deixar de sancionar o empresário incurso na prática infracional quando sua conduta importar efeitos benéficos à economia ou à determinada região".

Portanto, em síntese, o que se deve analisar, não é se ocorreu alguma forma de restrição, uma vez que não há ilegalidade per se na realização de uma restrição vertical. A questão que se deve colocar é se tal restrição beneficiará ou prejudicará o mercado, consequentemente, a própria concorrência. Esse pensamento foi exposto por Louis Dembitz Brandeis, como juiz da Suprema Corte Norte- Americana, ao decidir o caso Board of Trade of City of Chicago:

But the legality of an agreement or regulation cannot be determined by so simple
a test, as whether it restrains competition. Every agreement concerning trade,
every regulation of trade, restrains. To bind, to restrain, is of their very essence.
The true test of legality is whether the restraint imposed is such as merely
regulates, and perhaps thereby promotes competition, or whether it is such as
may suppress or even destroy competition. To determine that question, the court
must ordinarily consider the facts peculiar to the business to which the restraint
is applied, its condition before and after the restraint was imposed, the nature of
the restraint, and its effect, actual or probable. The history of the restraint, the
evil believed to exist, the reason for adopting the particular remedy, the purpose
or end sought to be attained, are all relevant facts. This is not because a good
intention will save an otherwise objectionable regulation, or the reverse, but
because knowledge of intent may help the court to interpret facts and to predict
consequences.

A caracterização da ilicitude dos atos por seus efeitos sobre o mercado, embora não gere maiores discussões no antitruste, já foi objeto de intensos debates, isto porque, "os operadores do direito por muito resistiram que determinados atos poderiam ou não ser ilítico, dependendo da empresa que o praticasse e/o do contexto do mercado" .

Para Herbert Hovenkamp , o melhor modo de determinar se restrições verticais são anticompetitivas e se, portanto, devem ser condenadas pelas legislações antitrustes "[...] é descobrir porque os fornecedores as realizam”. Além disso, diz o autor que:

The best way to determine when vertical restrictions are anticompetitive and ought to be condemned under the antitrust laws is to figure out why suppliers use them. As a basic premise, a supplier will use such restrictions only if they are profitable - that is, if the supplier can earn more with the restrictions than without them. Restrictions could be profitable for one of two reasons: 
NOÇõES BÁSICAS ACERCA DAS RESTRIÇÕES VERTICAIS NO DIREITO CONCORRENCIAL BRASILEIRO: DA LICITUDE À ILICITUDE “PER SE” Á LUZ DA RESOLUÇÃO Nº 20 DO CADE

DANILO BRUM DE MAGALHÃES JÚNIOR

because they increase the efficiency of the distribution system and thus help the supplier lower its costs;

(2) because they increase the supplier's market power and enable it to earn monopoly profits.

An antitrust policy that attempts to maximize the welfare of consumers would try to approve restrictions that had the first effect, and condemn those that had the second effect.

(...)

Unfortunately, it is not always easy to look at a particular vertical restriction and determine why a supplier uses it and what its effects might be. But there are a few factors that suggest anticompetitive potential. If none of these factors is present, we can assume that the restrictions are harmless.

Passando à análise da legislação concorrencial brasileira, a resolução $n^{\circ} 20$ do CADE, que como já vimos, trata precisamente de complementar a regulamentação dos Processos Administrativos referentes a condutas tidas como anticompetitiva, delineia os requisitos para a configuração de uma prática restritiva vertical ilegal. Esses pressupostos são os seguintes: (i) caracterização da conduta; (ii) análise das condições estruturais e/ou institucionais; (iii) Análise da conduta específica. Passamos então à análise das linhas gerais dos critérios apontados pela resolução $n^{\circ} 20$ do CADE.

\subsection{Caracterização da Conduta}

$O$ anexo II da resolução $\mathrm{n}^{\circ} 20$ do $\operatorname{CADE}(1999$, p. 7) descreve 2 passos para a caracterização da conduta: (i) Identificação da natureza da conduta e definição de seu enquadramento legal; e (ii) Verificação da existência de evidências suficientes da conduta nos autos.

Quanto à identificação da natureza da conduta e definição de seu enquadramento legal, a resolução estabelece que é necessário: (i)caracterização de sua natureza anticoncorrencial; (ii)identificar claramente a autoria da conduta; (iii)identificar os produtos e mercados envolvidos; (iv)sua racionalidade do ponto de vista de quem a pratica; (v)uma análise preliminar de seus efeitos prováveis sobre o (s) mercado(s); (vi)uma primeira proposta de enquadramento legal.

Quanto à verificação da existência de evidências suficientes da conduta nos autos, a resolução estabelece que "A adequada instrução do processo supõe que os autos reunam evidências suficientes da prática em questão, que não precisam restringir-se à prova documental, inclusive evidências circunstanciais como a ausência de racionalidade econômica para a adoção de conduta que não a da prática ilícita." 
NOÇÕES BÁSICAS ACERCA DAS RESTRIÇÕES VERTICAIS NO DIREITO CONCORRENCIAL BRASILEIRO: DA LICITUDE À ILICITUDE “PER SE" À LUZ DA RESOLUÇÃO N 20 DO CADE

DANILO BRUM DE MAGALHÃES JÚNIOR

Importante lembrar que a lei antitruste brasileira considera contrário à ordem econômica, qualquer ato (acordo, abuso, concentração, etc) que tenha por objeto ou possam produzir (ainda que não sejam alcançados) um dentre os seguintes efeitos: (i) limitar, falsear ou de qualquer forma prejudicar a livre concorrência ou a livre iniciativa; (ii) dominar mercado relevante de bens ou serviços; (iii) aumentar arbitrariamente os lucros; ou (iv) exercer de forma abusiva posição dominante, conforme disposto no artigo 36 da lei 12.529/11.

Além disso, como já vimos no item 2.2 deste artigo, § 30, menciona série de condutas que, caso impliquem a concomitante incidência do caput e seus incisos, consubstanciarão infrações à ordem econômica.

Por fim, conclui-se que para a caracterização de uma conduta restritiva vertical potencialmente lesiva à ordem econômica, é necessário a inclusão da conduta nas hipóteses do artigo 36 da lei Antitruste e o grau de probabilidade de que os efeitos ali descritos efetivamente ocorram.

\subsection{Análise das condições estruturais e/ou institucionais}

Nesta etapa é preciso analisar mais a fundo a probabilidade da restrição vertical em análise gerar os efeitos descritos no art. 36 da lei antitruste. Para tanto, é preciso verificar as condições estruturais e institucionais que influenciam essa potencialidade. Nesta etapa, portanto, devemos canalizar nossos esforços apenas na questão de identifica os fatores que devem ser levados em conta.

A resolução $n^{\circ} 20$ do CADE estabelece que quando se faz a análise das condições estruturais e/ou institucionais das restrições verticais, é necessário investigar: (i)Delimitação do(s) mercado(s) relevante(s); (ii)Estimativa das participações no(s) mercado(s) relevante(s); (iii)Análise das condições concorrenciais, efetivas e potenciais (barreiras à entrada), no(s) mercado(s) relevante(s) (incluindo condições institucionais); (iv)Avaliação das barreiras à entrada; (v)Exame do grau de exposição do(s) mercado(s) relevante(s) à concorrência por importações.

Diante dos requisitos apresentados, torna-se indispensável apresentar, dois conceitos importantes para a sua compreensão, quais sejam: mercado relevante e posição dominante. 
NOÇÕES BÁSICAS ACERCA DAS RESTRIÇÕES VERTICAIS NO DIREITO CONCORRENCIAL BRASILEIRO: DA LICITUDE À ILICITUDE “PER SE" À LUZ DA RESOLUÇÃ̃O N 20 DO CADE

DANILO BRUM DE MAGALHÃES JÚNIOR

\subsubsection{Mercado Relevante}

Além da resolução 20, diversas passagens da lei 12.529/11 referem-se ao termo mercado relevante. Nas palavras de Paula Forgioni , "O mercado relevante é aquele em que se travam as relações de concorrência ou atua o agente econômico cujo comportamento está sendo analisado". A partir do momento que os dispositivos legais fazem menção à restrição “da concorrência" para a caracterização do ilícito antitruste, devemos determinar de qual concorrência estamos tratando, uma vez que os atos anticoncorrenciais são práticas que só existem em concreto, ou seja, se referidas a um determinado mercado: ao mercado relevante.

Para o CADE, o termo mercado relevante refere-se a um conceito técnico que exprime a unidade de análise para a avaliação do poder de mercado. Nos termos da Cartilha do Cade :

“A definição de mercado relevante leva em consideração duas dimensões: a dimensão produto e a dimensão geográfica. A idéia por trás desse conceito é definir um espaço em que não seja possível a substituição do produto por outro, seja em razão do produto não ter substitutos, seja porque não é possível obtê-lo."

Para a delimitação do mercado relevante, devemos analisar dois aspectos complementares e indissociáveis: o mercado relevante geográfico e o mercado relevante material, ou mercado do produto.

A dimensão geográfica, para Calixto Salomão Filho , é “a mais importante na definição do mercado. É ela que permite, no mais das vezes, ampliar o mercado a ponto de descaracterizar a existência de poder, mesmo em presença de altos níveis de concentração no mercado originário". Para Paula Forgioni, o mercado relevante geográfico identifica-se como "o espaço físico onde se desenvolvem as relações de concorrência que são consideradas". 0 anexo $V$ da resolução $\mathrm{n}^{\circ} 15$ do CADE define mercado relevante geográfico como:

Um mercado relevante geográfico compreende a área em que as empresas ofertam e procuram produtos/serviços em condições de concorrência suficientemente homogêneas em termos de preços, preferências dos consumidores, características dos produtos/serviços. A definição de um mercado relevante geográfico exige também a identificação dos obstáculos à entrada de produtos ofertados por firmas situadas fora dessa área. As firmas capazes de iniciar a oferta de produtos/serviços na área considerada após uma pequena mas substancial elevação dos preços praticados fazem parte do mercado relevante geográfico. Nesse mesmo sentido, fazem parte de um mercado relevante geográfico, de um modo geral, todas as firmas levadas em 
NOÇõES BÁSICAS ACERCA DAS RESTRIÇÕES VERTICAIS NO DIREITO CONCORRENCIAL BRASILEIRO: DA LICITUDE À ILICITUDE “PER SE" À LUZ DA RESOLUÇÃO Nº 20 DO CADE

DANILO BRUM DE MAGALHÃES JÚNIOR

conta por ofertantes e demandantes nas negociações para a fixação dos preços e demais condições comerciais na área considerada.

O mesmo anexo define mercado relevante material, ou dos produtos, como aquele em que "todos os produtos/serviços considerados substituíveis entre si pelo consumidor devido às suas características, preços e utilização”. $O$ anexo $V$ da resolução $n^{\circ} 15$ do CADE ainda diz que “um mercado relevante do produto pode eventualmente ser composto por um certo número de produtos/serviços que apresentam características físicas, técnicas ou de comercialização que recomendem o agrupamento".

Para Paula Forgioni , mercado relevante material é "aquele em que o agente econômico enfrenta a concorrência, considerando o bem ou serviço que oferece. Sua delimitação, a exemplo do mercado relevante geográfico, parte da identificação das relações de concorrência".

Como critério para delimitação demarcar o mercado relevante, o Guia para Análise Econômica de Atos de concentração horizontal, anexo à portaria conjunta SDE/SEAE 50 de 2001 diz que:

A definição de um mercado relevante é o processo de identificação do conjunto de agentes econômicos, consumidores e produtores, que efetivamente limitam as decisões referentes a preços e quantidades da empresa resultante da operação. Dentro dos limites de um mercado, a reação dos consumidores e produtores a mudanças nos preços relativos - o grau de substituição entre os produtos ou fontes de produtores - é maior do que fora destes limites. 0 teste "monopolista hipotético", descrito adiante, é o instrumental analítico utilizado para se aferir o grau de substitutibilidade entre bens ou serviços e, como tal, para a definição do mercado relevante.

\subsubsection{Posição Dominante}

Posição dominante, em síntese, é decorrência e, ao mesmo tempo, se identifica como o poder detido pelo agente, no mercado, "que the assegura a possibilidade de atuar com um comportamento independente e indiferente em relação a outros agentes, impermeável às leis do mercado" .

Nos termos do § 20 do artigo 36 da Lei Antitruste, "Presume-se posição dominante sempre que uma empresa ou grupo de empresas for capaz de alterar unilateral ou coordenadamente as condições de mercado ou quando controlar 20\% (vinte por cento) ou mais do mercado relevante, podendo este percentual ser alterado pelo CADE para setores específicos da economia". 
NOÇõES BÁSICAS ACERCA DAS RESTRIÇÕES VERTICAIS NO DIREITO CONCORRENCIAL BRASILEIRO: DA LICITUDE À ILICITUDE “PER SE" À LUZ DA RESOLUÇÃO Nº 20 DO CADE

DANILO BRUM DE MAGALHÃES JÚNIOR

No Brasil, a posição dominante por si só não é punível, apenas seu abuso (e não o uso). $0 \S 1^{\circ}$ do artigo 36 da lei $12.29 / 11$ diz que "A conquista de mercado resultante de processo natural fundado na maior eficiência de agente econômico em relação a seus competidores não caracteriza o ilícito previsto no inciso II do caput deste artigo".

Ademais, sustentam GABAN e DOMINGUES que a posição dominante é requisito para a configuração das restrições verticais ilícitas. Entretanto, esta interpretação não é unânimime. Para Calixto Salomão Filho , por exemplo, o poder de mercado não é requisito necessário nem suficiente para a caracterização do ilícito. Ele afirma que há apenas um requisito, qual seja a coerção, que se manifesta através da dependência econômica. A dependência, por sua vez, pode ter distintas causas: poder de mercado, assimetrias de informação, retornos crescentes de escala etc. A resolução $\mathrm{n}^{\circ} 20$ do CADE, por sua vez, diz que as práticas verticais pressupõem "a existência de poder de mercado sobre o mercado relevante de origem".

$O$ entendimento do CADE é de que "Não se pode infringir a ordem econômica quem não disponha de poder econômico capaz de, por seu abuso, restringir ou limitar a livre concorrência no mercado relevante".

Neste sentido, conclui-se que: (i) a existência de uma prática restritiva vertical ilícita pressupõe a existência de poder de mercado sobre o mercado relevante de origem. (ii) que, nos termos do $§ 20$ do artigo 36 da Lei 12.529/11, "Presume-se posição dominante sempre que uma empresa ou grupo de empresas for capaz de alterar unilateral ou coordenadamente as condições de mercado ou quando controlar 20\% (vinte por cento) ou mais do mercado relevante, podendo este percentual ser alterado pelo Cade para setores específicos da economia"; e (iii) A posição dominante não é ilícita per se, apenas seu abuso é punível.

\subsection{Análise da conduta específica}

A caracterização de uma prática restritiva vertical como ilegal conclui-se com o terceiro e último requisito, ou seja, a análise da conduta específica. Esta análise, como veremos, consiste na ponderação dos efeitos anticompetitivos e das possíveis eficiências das condutas.

A resolução $n^{\circ} 20$ do CADE diz que embora as restrições constituam, em princípio, restrições à livre concorrência, elas também podem apresentar benefícios (eficiências econômicas) que "devem ser ponderados vis-à-vis os efeitos potenciais anticompetitivos, de acordo com o princípio da razoabilidade". 
NOÇõES BÁSICAS ACERCA DAS RESTRIÇÕES VERTICAIS NO DIREITO CONCORRENCIAL BRASILEIRO: DA LICITUDE À ILICITUDE “PER SE" À LUZ DA RESOLUÇÃ̃O Nº 20 DO CADE

DANILO BRUM DE MAGALHÃES JÚNIOR

Sobre o assunto Priscila Brólio Gonçalves diz que este é o caráter polêmico no direito concorrencial. Isso porque, quando falamos em efeitos das restrições verticais, temos:

De um lado, entre os eventuais efeitos indesejáveis das restrições verticais, mencionamse os incentivos à formação de cartéis e a eliminação de entraves ao monitoramento, a redução da concorrência entre as diferentes marcas e também entre os distribuidores da mesma marca), a uniformização de preços e a elevação de barreiras à entrada no mercado.

De outro lado, como possíveis benefícios e eficiências associados às restrições verticais, têm-se citado as reduções de preços decorrentes de economias de escala e de incentivos à entrada de novos concorrentes no mercado, a promoção do produto através da garantia de margens mínimas aos vendedores, o aumento da concorrência entre as marcas, a eliminação das margens duplas, a eliminação do problema do carona (free riding) e redução de barreiras à entrada.

Visando solucionar uma decisão adequada, a resolução $n^{\circ} 20$ do CADE (1999, p. 14) diz que a ponderação deve ser feita de acordo com o princípio da razoabilidade tendo como objetivo verificar se as eficiências são suficientes para compensar os efeitos anticompetitivos, permitindo, assim, considerar lícita a conduta em questão.

O poder judiciário, por meio do voto-vista da ministra Nancy Andrighi no REsp 261.155SP afirmou que a regra da razão "constitui uma forma de interpretação lógica, por meio da qual os efeitos restritivos da concorrência são comparados com os efeitos pró-competitivos."

Diante disto, conclui-se, que de acordo com a regra da razão, uma prática restritiva (horizontal ou vertical) só pode ser considerada como nociva à concorrência após uma análise de sua razoabilidade no contexto econômico em que a prática se insira. Essa regra envolve, portanto, uma complexa análise de custo e benefício que as práticas restritivas podem trazer .

\subsubsection{Identificação das Eficiências Econômicas}

As restrições verticais podem ser promotoras de eficiências econômicas na medida em que ajudam a eliminar determinadas formas de externalidades verticais na relação fabricantedistribuidor, bem como externalidades horizontais entre distribuidores e/ou fabricantes, derivadas, por exemplo, de "free-riding" entre eles. A existência de eficiências econômicas atreladas à utilização de uma prática restritiva, portanto, é a grande justificativa utilizada pelas empresas para a licitude de sua conduta. 
NOÇÕES BÁSICAS ACERCA DAS RESTRIÇÕES VERTICAIS NO DIREITO CONCORRENCIAL BRASILEIRO: DA LICITUDE À ILICITUDE "PER SE" À LUZ DA RESOLUÇÃO No 20 DO CADE

DANILO BRUM DE MAGALHÃES JÚNIOR

Sucintamente pode se definir o conceito de eficiência como toda consequência positiva de um ponto de vista econômico, advinda da efetiva ou potencial aplicação de um ato econômico ao mercado. A resolução $n^{\circ} 15$ do CADE traz a seguinte definição de eficiências:

Entende-se por eficiências aquelas reduções de custos de qualquer natureza, estimáveis quantitativamente e intrínsecas ao tipo de operação de que se trata, que não poderiam ser obtidas apenas por meio de esforço interno.

Calixto Salmoão Filho faz uma distinção entre eficiência alocativa e eficiência produtiva. A eficiência alocativa "[...] relaciona-se com a distribuição dos recursos na sociedade. Não se deve confundir a questão com o problema da distribuição de renda e de riquezas, que para os neoclássicos nada tem a ver com o direito antitruste". A eficiência alocatícia relacionase com o modo que o ganho de bem estar se difunde na sociedade, ela representa a melhora par aos consumidores de um determinado produto.

Esta melhoria pode se dar através da redução de preços, do crescimento da disponibilidade dos mesmos, melhoras em serviços pós-venda, etc. Segundo Calixto, “[...] verificar se existe eficiência alocativa é simplesmente determinar se os recursos estão empregados naquelas atividades que os consumidores mais apreciam ou necessitam."

Já as eficiências produtivas, por outro lado, são aquelas focadas na utilização da capacidade e recursos produtivos de uma determinada empresa. Ela contempla as reduções de custos de produção, seja pelo crescimento de escala, seja pela redução do custo de pesquisa e desenvolvimento, entre outros fatores .

Outra discussão interessante na doutrina antitruste é referente à necessidade da transferência do ganho do bem estar gerado para as empresas aos consumidores como requisito para que esta eficiência seja válida no sentido de tornar lícita a conduta avaliada. Neste sentido, diz Luís Fernando Schuartz :

A questão é a seguinte: deveriam as autoridades antitruste se satisfazer com a demonstração da geração de eficiências internalizáveis ou também é necessário mostrar concretamente seu potencial de conversão em benefícios aos consumidores?

$[\ldots]$

Para aqueles que entendem que basta a demonstração de que a conduta investigada é fonte potencial de eficiências, o interesse se esgota nas prováveis reduções de custo e/ou incrementos da taxa ou ritmo das inovações; para os que insistem no caráter necessário mas não suficiente desse potencial, as principais variáveis observadas são preço, qualidade e/ou diversidade dos bens e serviços ofertados (efeitos sobre os custos têm, aqui uma função apenas instrumental), i.e. variáveis relacionadas a ganhos imediatos para o consumidor. 
NOÇÕES BÁSICAS ACERCA DAS RESTRIÇÕES VERTICAIS NO DIREITO CONCORRENCIAL BRASILEIRO: DA LICITUDE À ILICITUDE “PER SE" À LUZ DA RESOLUÇÃO N 20 DO CADE

DANILO BRUM DE MAGALHÃES JÚNIOR

O autor conclui o pensamento expondo sua preferência por uma via mista entre os dois pontos de vista. Segundo ele, se acatarmos integralmente a necessidade da distribuição, estará sendo retirada do administrador a necessária autonomia para gerir seus negócios, o que pode levar à sua ruína. Já o contrário, se não fosse necessária a distribuição, estaríamos legitimando a concentração de renda nas mãos dos detentores do poder de mercado, e indo de encontro ao objetivo da legislação antitruste que é a proteção do mercado e por conseguinte dos consumidores.

Sobre o assunto, Calixto Salomão Filho diz que “[...] Talvez seja mais correto, ainda, afirmar que é a repartição dos ganhos de eficiência com o consumidor o único indicador que permite comprovar a efetiva existência desses ganhos.".

A resolução $\mathrm{n}^{\circ} 20$ do CADE por meio do item 3.2.2, trata das possíveis eficiências econômicas geradas pelas condutas anticompetittivas verticais.

No caso das práticas verticais, os principais dentre os possíveis benefícios/eficiências a elas associados consistem na redução de custos de transação, expressa na detenção de comportamentos oportunistas ("free rider") de modo a preservar/incentivar a qualidade dos serviços nos mercados "alvo" (distribuição, pós-venda, etc.) e proteger a reputação e os investimentos em ativos específicos de empresas no mercado "de origem". Em certos casos podem ainda estimular a consecução de economias de escala e de escopo no mercado "alvo", ou ainda proteger o desenvolvimento tecnológico no mercado "de origem". No caso específico da fixação de preços máximos de revenda, é preciso considerar a hipótese de que ela permita eliminar a possibilidade de exercício de poder de mercado por parte dos distribuidores.

$\mathrm{Na}$ avaliação das possíveis eficiências econômica das práticas restritivas verticais, o referido item diz que "deve-se investigar se as relações contratuais entre as empresas em questão, na ausência da prática sob análise, são vulneráveis a ações oportunistas de qualquer uma delas". Para tanto, seria exigido, conforme o item 3.2.2 da resolução número 20 do CADE, informações sobre:

- $\quad$ características do produto ou serviço que está sendo transacionado, de maneira a estimar os custos que cada parte de um hipotético contrato simples de compra e venda teria em monitorar o cumprimento dos termos contratuais pela outra parte;

- $\quad$ os custos de busca de alternativas para comprar ou vender o mesmo produto ou serviço, caso o hipotético contrato simples de compra e venda seja desfeito. Estes custos dependem da realização de investimentos em ativos específicos por uma ou ambas as partes, ou seja, ativos especializados que perdem valor quando utilizados em transações com outros 
NOÇõES BÁSICAS ACERCA DAS RESTRIÇÕES VERTICAIS NO DIREITO CONCORRENCIAL BRASILEIRO: DA LICITUDE À ILICITUDE “PER SE" À LUZ DA RESOLUÇÃO N 20 DO CADE

DANILO BRUM DE MAGALHÃES JÚNIOR

agentes. A especificidade dos ativos pode decorrer de: (i) localização geográfica, (ii) características físicas de equipamentos, (iii) capacitações tecnológicas especializadas, (iv) capacidade produtiva dimensionada para a demanda de um grande cliente."

Tem-se, assim, que as restrições verticais são passíveis de gerar eficiência, conceito este entendido como toda consequência positiva de um ponto de vista econômico, advinda da efetiva ou potencial aplicação de um ato econômico ao mercado e que, nos termos do item 3.2.2 da resolução $n^{\circ} 20$ do CADE, “deve-se investigar se as relações contratuais entre as empresas em questão, na ausência da prática sob análise, são vulneráveis a ações oportunistas de qualquer uma delas" para avaliar as possíveis eficiências econômicas advindas de determinada prática restritiva vertical.

\subsubsection{Identificação dos Efeitos Anticoncorrenciais}

As práticas restritivas verticais podem ser anticompetitivas quando reduzem a concorrência, mediante seus efeitos horizontais, entre fabricantes e/ou distribuidores, reduzindo as opções e o bem estar dos consumidores. Por exemplo, contratos de exclusividade podem inibir a entrada de novos competidores ou ainda a exclusividade territorial pode gerar poder de monopólio.

A Resolução $n^{\circ} 20$ do CADE, além de elencar uma lista de possíveis eficiências de práticas restritivas, elenca ainda uma lista de possíveis efeitos anticoncorrenciais que podem advir de práticas verticais

[...] a facilitação da implementação de práticas concertadas (cartéis, etc.), ou o reforço unilateral de poder de mercado de uma empresa dominante, no mercado relevante "de origem" (comum a todas as práticas); o "bloqueio" do mercado relevante "alvo" da prática para concorrentes efetivos ou potenciais (aumento das barreiras à entrada), inclusive por aumento de custos de rivais; a exploração monopolista dos usuários de serviços pós-venda; e a atenuação da concorrência entre ou intra-marcas.

$\mathrm{Na}$ investigação dos possíveis efeitos anticompetitivos das práticas verticais, a referida resolução diz ainda que o CADE deverá levar em consideração, os seguintes dados: (i) A proporção do(s) mercado(s) relevante(s) alvo(s) atingida pelas condutas verticais investigadas; 
NOÇÕES BÁSICAS ACERCA DAS RESTRIÇÕES VERTICAIS NO DIREITO CONCORRENCIAL BRASILEIRO: DA LICITUDE À ILICITUDE “PER SE" À LUZ DA RESOLUÇÃO N 20 DO CADE

DANILO BRUM DE MAGALHÃES JÚNIOR

(ii) A duração das práticas restritivas; (iii) A magnitude das barreiras à entrada no(s) mercado(s) envolvido(s) na prática restritiva;

\subsubsection{Ponderação dos Efeitos Anticompetitivos e das Eficiências Econômicas - A regra da razão}

O último passo da análise é fazer a ponderação entre os efeitos anticompetitivos e as eficiências econômicas. Esta ponderação é feita pelo que a doutrina chama de regra da razão, que deriva do sistema americano "rule of reason". Para Paula Forgioni, pela regra da razão, "somente são consideradas ilegais as práticas que restigrem a concorrência de forma não razoável. A contrario sensu, são permitidas as práticas que não impliquem obstáculos desarrazoado ao livre comércio.".

Das orientações acima, temos que a ponderação deve seguir três orientações: (i) deve haver um análise criteriosa e minuciosa; (ii) a ponderação pode ser em grande parte qualitativa (visto que muitos dos efeitos são potenciais e que os custos de transação são de difícil mensuração); e (iii) é preciso, para concluir pela licitude da medida, que as eficiências sejam "suficientes para compensar" os efeitos competitivos.

Portanto, é evidente que é pouca a quantidade de informação sobre como deve ser praticada a ponderação dos efeitos anticompetitivos e das eficiências. Esperamos que o SBDC modernize este ponto da resolução com a finalidade de fornecer um guia mais seguro para a análise de restrições verticais, em especial quanto à ponderação.

\section{CONCLUSÃO}

O presente artigo buscou fazer uma breve revisão da literatura antitruste, bem como de determinados aspectos operacionais e legais no âmbito da legislação brasileira de defesa da concorrência para tentar demonstrar noções básicas acerca do que são as restrições verticais, e como se dá a análise de sua (i)licitude à luz do direito concorrencial brasileiro.

Do estudo feito, constatou-se que as restrições verticais são estipulações contratuais, geralmente inseridas por produtores/ofertantes de bens ou serviços em determinado mercado sobre mercados relacionados verticalmente ao longo da cadeia produtiva, que restringem a liberdade de atuação de uma das partes. 
NOÇÕES BÁSICAS ACERCA DAS RESTRIÇÕES VERTICAIS NO DIREITO CONCORRENCIAL BRASILEIRO: DA LICITUDE À ILICITUDE “PER SE" À LUZ DA RESOLUÇÃO N 20 DO CADE

DANILO BRUM DE MAGALHÃES JÚNIOR

Tais condutas podem gerar diversos efeitos, sejam eles benéficos ou prejuidiciais à concorrência. Os principais possíveis efeitos anticoncorrenciais identificados foram o reforço unilateral de poder de mercado de uma empresa dominante no mercado relevante de origem, o bloqueio do mercado para concorrentes efetivos ou potenciais (aumento das barreiras à entrada), inclusive por aumento de custos de rivais e a atenuação da concorrência inter ou intramarcas. Os principais dentre os possíveis benefícios/eficiências a elas associados consistem na redução de custos de transação, eliminação de externalidades e nos ganhos de economias de escala e de escopo no mercado alvo.

Quando tratamos de restrições verticais, bem como de qualquer outro assunto relacionado à disciplina concorrencial, precisamos definir, ou pelo menos procurar definir, as fronteiras entre o lícito e o ilícito no direito brasileiro. Para tanto, deve-se ter presente o impacto, ou efeitos, das diversas condutas sobre o mercado. Mas quando se trata da ilicitude das restrições verticais, estamos adentrando em um dos pontos mais polêmicos do direito antitruste, isto porque, como vimos, nem a doutrina e tampouco a jurisprudência encontram-se perto de consenso sobre até que ponto as restrições verticais gerem efeitos benéficos para a economia capazes de suplantar a restrição à concorrência a que dão origem.

Sobre o assunto, a legislação brasileira, em especial a resolução $n^{\circ} 20$ do CADE, determina que quando da análise das restrições verticais, precisamos partir do princípio de que as restrições verticais não necessariamente são um ilícito, nem tampouco uma prática lícita, isto porque, acompanhando a evolução mundial do direito antitruste, a resolução $\mathrm{n}^{\circ} 20$ acaba exigindo a necessidade de demonstração efetiva dos efeitos anticoncorrenciais e das possíveis eficiências econômicas da conduta para então fazer uma ponderação entre estes à luz do principio da razoabilidade - regra da razão -, ou seja, o CADE poderá deixar de sancionar o agente econômico incurso na prática infracional quando sua conduta importar efeitos benéficos à economia ou à determinada região .

A resolução $n^{\circ} 20$ do $C A D E$, é o que podemos chamar de guia de análises de restrições verticais no Brasil. Esta resolução foi um avanço muito importante no tratamento das restrições verticais no Brasil à sua época, visto que, trouxe importantes conceitos, como a regra da razão. Entretanto, passados quase quinze anos, a resolução ainda não foi editada e, portanto, ainda não estabelece, como vimos, diretivas claras sobre a aplicabilidade da regra da razão e da demonstração de eficiências e efeitos anticompetitivos, dando total discricionariedade ao CADE, permitindo assim, por parte da autoridade antitruste brasileira, interpretações variadas sobre o que é considerado fechamento de mercado e que informação é suficiente para concluir que ele 
NOÇõES BÁSICAS ACERCA DAS RESTRIÇÕES VERTICAIS NO DIREITO CONCORRENCIAL BRASILEIRO: DA LICITUDE À ILICITUDE “PER SE" À LUZ DA RESOLUÇÃ̃O Nº 20 DO CADE

DANILO BRUM DE MAGALHÃES JÚNIOR

ocorreu, por exemplo. Ressalta-se, no entanto, que este não é um problema específico do controle de condutas verticais, é uma problemática do direito concorrencial como um todo uma vez que é difícil falarmos em certezas no direito econômico.

O CADE já demonstrou a intenção de, em breve, lançar um novo guia para práticas restritivas verticais. Espera-se deste guia uma renovação significativa, no sentido de, principalmente, (i) facilitar o exame das eficiências trazidas pela conduta restritiva investigada; (ii) de demonstrar claramente os possíveis efeitos anticompetitivos da conduta e; (iii) de como deve ser feita a ponderação destes.

Tais sugestões são necessárias, uma vez que, como vimos, as restrições verticais são práticas diárias invitáveis em nosso sistema e precisam de uma regulamentação que transmita segurança, até mesmo para que todas as pessoas possam utilizar delas de forma correta, sem ter a incerteza de estar ou não causando dano à concorrência.

\section{REFERÊNCIAS}

AZEVEDO, Paulo Furquim de. Restrições verticais e defesa da concorrência: a experiência brasileira. São Paulo: Fundação Getúlio Vargas, Escola de Economia de São Paulo, 2010. Disponível em: http://bibliotecadigital.fgv.br/dspace/handle/10438/6895. Acesso em: 12 dez. 2013.

BRASIL. Superior Tribunal de Justiça. Recurso especial $n^{\circ}$ 261155-SP. Recorrente: Marialda Meyer de Castro Araújo. Recorrida: Unimed Rio Claro Cooperativa de Trabalho Médico. Relator: Min. Ruy Rosado de Aguiar. Brasília, 10 de março 2004. Disponível em:

<https://ww2.stj.jus.br/processo/revistaeletronica/inteiroteor?num_registro=2000/00532983\&data=3/5/2004>. Acesso em: 12 dez. 2013.

BRUNA, S. V., O Poder Econômico e a Conceituação do Abuso em seu Exercício. São Paulo: Editora RT, 1997.

CADE. Guia Prático do Cade: a defesa da concorrência no Brasil - 3. Ed. Revista, ampliada a bilíngue - São Paulo: CIEE, 2007.

CADE. Resolução $\mathrm{n}^{\circ} 15$, de 19 de agosto de 1998. Disciplina as formalidades e os procedimentos no CADE, relativos aos atos de que trata o artigo 54 da Lei 8.884, de 11 de junho de 1994. Disponível em:

http: / / www.cade.gov.br/upload/Resolu\%C3\%A7\%C3\%A30\%20n\%C2\%BA\%2015,\%20de\%2019\%20de\%2 0agosto\%20de\%201998.pdf 
NOÇÕES BÁSICAS ACERCA DAS RESTRIÇÕES VERTICAIS NO DIREITO CONCORRENCIAL BRASILEIRO: DA LICITUDE À ILICITUDE “PER SE” Á LUZ DA RESOLUÇÃO N 20 DO CADE

DANILO BRUM DE MAGALHÃES JÚNIOR

CADE. Resolução $n^{\circ} 20$, de 9 de junho de 1999, Dispõe, de forma complementar, sobre o Processo Administrativo, nos termos do art. 51 da Lei 8.884, de 11 de junho de 1994. Disponível em:

http://www.cade.gov.br/upload/Resolu\%C3\%A7\%C3\%A30\%20n\%C2\%BA\%2020,\%20de\%209\%20de\%20 junho\%20de\%201999.pdf

COMUNIDADE EUROPÉIA. Aplicação dos arts. $81^{\circ}$ e $82^{\circ}$ do Tratado CE. Disponível em: http://europa.eu/legislation_summaries/other/l26042_pt.htm

COMUNIDADE EUROPÉIA. Orientações relativas às restrições verticais. Disponível em: http://europa.eu/legislation_summaries/other/l26061_pt.htm

COMUNIDADE EUROPÉIA. Tratado da comunidade europeia. Disponível em: http://eurlex.europa.eu/pt/treaties/dat/12002E/pdf/12002E_PT.pdf

CORRÊA, Daniel Rocha. Práticas restritivas verticais: contributo da experiência europeia para o direito da concorrência brasileiro. Revista de Informação Legislativa, V. 181, p. 277-296, 2009.

CORRÊA, Daniel Rocha. Apontamentos Sobre O Princípio Constitucional Da Liberdade De Concorrência. Nomos. Revista do Curso de Mestrado em Direito da UFC, Fortaleza, Vol. 29.1, p.13-28, jan./jun. 2009.

FERRAZ JUNIOR, Tércio Sampaio. Da Abusividade do Poder Econômico. Revista de Direito Econômico, Brasília, SD, p. 23-30, 1995.

FERRAZ JUNIOR, Tércio Sampaio. Lei de Defesa da Concorrência - Origem Histórica e Base Constitucional. Revista dos Mestrados em Direito Econômico da UFBA, v. 2, p. 65, 1992. Disponível em: http://www.terciosampaioferrazjr.com.br/?q=/publicacoes-cientificas/132

FORGIONI, Paula A. Os fundamentos do antitruste .5. ed. São Paulo: Revista dos Tribunais, 2012.

FORGIONI, Paula A. Direito Concorrencial e Restrições Verticais. São Paulo: Revista dos Tribunais, 2007.

FOX, E. M. e SULLIVAN, L. A: Cases and materials on antitrust. Minnesota, West Publishing Co.. 1989

GABAN, Eduardo Molan; DOMINGUES, Juliana Oliveira. Direito Antitruste: O Combate a Cartéis. São Paulo: Saraiva, 2009.

GONÇALVES, Priscila Brólio. Fixação e sugestão de preços de revenda em contratos de distribuição: análise dos aspectos concorrenciais. SP. Editora Singular. 2002

GRAU, Eros Roberto. A Ordem Econômica na Constituição de 1988 - Interpretação e Crítica. 7. ed. São Paulo: Malheiros, 2002.

HOVENKAMP, Hebert. Federal antitrust policy - the law of competition and its practice. St. Paul: Hornbook series, West Publishing CO., 1999 
NOÇÕES BÁSICAS ACERCA DAS RESTRIÇÕES VERTICAIS NO DIREITO CONCORRENCIAL BRASILEIRO: DA LICITUDE À ILICITUDE “PER SE” Á LUZ DA RESOLUÇÃO N 20 DO CADE

DANILO BRUM DE MAGALHÃES JÚNIOR

LIMA, Ticiana Nogueira da Cruz. O processo administrativo no CADE e os problemas da regulação concorrencial brasileira. São Paulo, 2009. Dissertação (Mestrado em Direito) Faculdade de Direito da Universidade de São Paulo - USP, São Paulo / SP, 2009.Disponível em: http://www.teses.usp.br/teses/disponiveis/2/2134/tde-06072011-094418/fr.php. Acesso em: 12 out. 2013.

MUNHOS, Carolina Pancotto Bohrer. Direito, livre concorrência e desenvolvimento. São Paulo: Lex Editora, 2006.

NUSDEO, Fábio. Fundamentos para uma codificação do direito econômico. São Paulo: Saraiva, 1977.

PROENÇA, José Marcelo Martins. Concentração empresarial e o Direito da Concorrência. São Paulo: Saraiva, 2001.

ROMERO, Anna Paula Berhnes. As restrições verticais e a análise econômica do direito. Revista Direito GV, v. 2, p. 11-35, 2006.

SALOMÃO FILHO, Calixto. Direito Concorrencial: As Condutas. $1^{\text {a }}$ Ed. São Paulo: Malheiros, 2007. SALOMÃO FILHO, Calixto. Direito Concorrencial: As estruturas. $3^{\text {a }}$.ed. São Paulo: Malheiros, 1998.

SCHUARTZ, Luis Fernando. Ilícito antitruste e acordos entre concorrentes. In: POSSAS, Mário L. (org.). Ensaios sobre economia e Direito da Concorrência. São Paulo: Singular, 2002.

TAVARES, André Ramos. Direito constitucional econômico. São Paulo: Ed. Método, 2003.

ULHOA COELHO, Fábio. Direito antitruste brasileiro. São Paulo: Saraiva, 1995.

U.S. Department of Justice and the Federal Trade Commission. Antitrust Guidelines for Collaborations Among Competitors, 2000. Disponível em:

<http://www.ftc.gov/os/2000/04/ftcdojguidelines.pdf> Acesso em: 15 dez. 2013.

U.S. Department of Justice and the Federal Trade Commission. Horizontal Merger Guidelines, 1992. Disponível em: <http://www.justice.gov/atr/public/guidelines/horiz_book/hmg1.html> Acesso em: 16 dez. 2013.

Recebido em: 21.12.2013

Correções solicitadas em: 14.04.2014

Aprovado em: 04.06.2014 